\title{
Compreendendo a doença para além do discurso patológico
}

\section{Understanding disease beyond the pathological discourse}

\author{
Marcelo Gruman \\ Antropólogo da Fundação Nacional de Artes/Ministério da Cultura. \\ marcelogruman@gmail.com
}

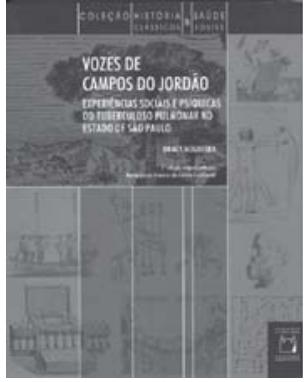

NOGUEIRA, Oracy. Vozes de Campos do Jordão: experiências sociais e psíquicas do tuberculoso pulmonar no estado de São Paulo. Rio de Janeiro: Editora Fiocruz, 2009. 220p.
$\mathrm{O}$ livro Vozes de Campos do Jordão: experiências sociais e psíquicas do tuberculoso pulmonar no estado de São Paulo, de Oracy Nogueira, foi, originalmente, uma dissertação de mestrado defendida na Escola Livre de Sociologia e Política, em 1945. É um estudo de caso que pretendeu articular a pesquisa de um universo particular de doentes tuberculosos em uma estação de cura à proposta de compreender a doença como experiência social. A função de cidade de cura imputada a Campos do Jordão, situada a cerca de 1.600 metros de altitude e de clima seco e ameno, foi oficializada em 1926, quando o governo do estado de São Paulo criou a prefeitura sanitária local. Como bem coloca a organizadora do volume, a antropóloga Maria Laura Viveiros de Castro Cavalcanti, por meio da observação participante, da análise de histórias de vida e de documentos pessoais, de questionários e quadros estatísticos, Nogueira "desvenda um conjunto de situações e fatores extraorgânicos que instauram a tuberculose e, por extensão,

a doença em si como tema pertinente à investigação sociológica" (p.13).

O próprio autor deixa claro, na nota para a segunda edição, que seu interesse se situa nas dimensões sociais e subjetivas da doença, ao privilegiar os processos de redefinição e readaptação dos indivíduos ao mundo social segregado produzido pela doença: "Não pretendi estudar os fatores de incidência da tuberculose, mesmo por que havia consenso praticamente unânime quanto à importância da subnutrição e da exaustão física e, consequentemente, do pauperismo, nesse condicionamento, além de não dispensar o problema de etiologia o concurso direto dos médicos. ... Mais restritamente, meu objeto real eram os doentes agrupados, constituindo uma comunidade própria, como em Campos do Jordão" (p.33). Sugere, assim, uma nova perspectiva no estudo do comportamento e dos 'traços de personalidade' do tuberculoso pulmonar, determinando a importância do deslocamento do doente de seu antigo círculo de relações sociais para outro, diferente. O 'ambiente tuberculoso' é o último estágio do processo de 'tornar-se doente', em que são estabelecidas relações duradouras entre doentes e profissionais de saúde marcadas por atitudes, estereótipos, tabus e representações que então cercavam a tuberculose.

Nogueira apresenta, na primeira parte do texto, algumas ideias e atitudes correntes sobre a tuberculose pulmonar no estado de São Paulo à época da pesquisa, realizada em 
1944. A primeira delas é a da doença como 'sanção sobrenatural', implicando uma ideia de impureza ou culpa por parte do doente, constituindo a primeira em uma 'sanção' ou 'castigo' sobre o 'pecador' ou 'transgressor' de supostas leis divinas. Tal concepção vai ao encontro do que Mary Douglas (1976) afirma em seu clássico Pureza e perigo: que a 'sujeira' é tudo aquilo que desafia um dado sistema de classificação da realidade, que divide o mundo entre 'sagrado' e 'profano', 'puro' e 'impuro'. O doente, portanto, seria a representação simbólica da transgressão.

Ainda com relação às noções de 'perigo', 'pureza' e 'sujeira', no capítulo intitulado "Algumas manifestações psicológicas dos doentes", Nogueira afirma que o doente, imediatamente após a descoberta da enfermidade, se vê suspenso entre dois grupos que se excluem mutuamente: o dos 'sãos', ao qual ele deixou de pertencer, contra a vontade; e o dos 'doentes', em relação ao qual sua atitude é de oposição ou aversão. Reluta em aceitar a identificação de sua doença como tuberculose pulmonar e continua a olhar os companheiros de enfermidade do ponto de vista das pessoas 'sãs'. O doente é acometido de uma 'impressão de intocabilidade', envolvendo a noção de perigo tanto para si como para os outros. Eles próprios tomam, por exemplo, medidas higiênicas que evitem o contágio da doença, como a separação de objetos de mesa e outros de uso pessoal e o desvio do rosto ao falar com a pessoa 'sã'.

Apresentam características psicológicas daquilo que Everett Stonequist (1948) cunhou de 'homem marginal', ao referir-se especificamente aos judeus que se viram livres com a queda dos muros dos guetos medievais. Esse indivíduo, doente, apresenta um novo tipo de personalidade: é um híbrido cultural. Participa, inicialmente, da vida e das tradições de dois povos (no nosso caso, 'sãos' e 'doentes'), não rompendo completamente com o seu passado e não sendo aceito ou se aceitando inteiramente pelos novos companheiros. É um homem à margem de duas sociedades/grupos, que não se interpenetram.

A segunda ideia é a da tuberculose como 'condição romântica', que empolgou poetas e prosadores do século XIX, por conta da 'beleza romântica do tísico'. A terceira e última ideia é a da tuberculose como 'flagelo social', quer dizer, o tuberculoso como desafio à concepção do tipo humano ideal, robusto e atlético, colocando em perigo valores altamente positivos, sobretudo, a partir de uma visão de mundo eugenista. A correção dessa situação seria possível somente por meio da ação coletiva, sendo a tuberculose entendida como 'problema social'.

A incorporação das representações sociais correntes sobre a doença, pelo próprio doente, leva à constante preocupação em manter segredo em torno do próprio 'caso' quando ainda em convívio no meio dos 'sãos'. Diz Nogueira que, "sabendo do pavor que as pessoas 'sãs' têm de sua doença e dos transtornos que lhe adviriam às relações sociais se seu estado de saúde se tornasse conhecido, e sendo-lhes difícil, se não mesmo impossível, prescindir de tais relações, os doentes se veem na contingência de 'passar' por pessoas 'sãs', a fim de preservá-las" (p.61).

O autor desnuda, nessa passagem, o que mais tarde Erving Goffman (1988) vai desenvolver a respeito da noção de estigma. O próprio Nogueira, na nota para a segunda edição, admite que suas observações e reflexões teriam sido "altamente beneficiadas se já dispusesse da elaboração de Goffman sobre o estigma" (p.30). No estudo sobre o estigma, Goffman 
analisa o processo de definição de uma situação social e as expectativas quanto ao comportamento dos que se encaixam na categoria de pessoas que se espera serem frequentadoras de tal ambiente. O estigma é definido como um atributo profundamente depreciativo que não existe em si, mas apenas enquanto parte de uma linguagem compartilhada pelos membros do grupo de que falamos na sua relação com os que dele se afastam.

Um ponto interessante na análise de Goffman, refletido na importância de 'manter segredo' sobre 'o caso', é a possibilidade de o indivíduo manipular o suposto estigma (no caso ora em análise, a tuberculose) e sua representação quando a diferença não está imediatamente visível aos interlocutores. O indivíduo permanecerá 'desacreditável' e não 'desacreditado', ou seja, a manipulação da informação transmitida molda a percepção social a partir da qual 'outros significativos' construirão sua imagem ao ocultar as 'deficiências'. O indivíduo permanece com uma 'identidade social virtual' até o momento em que os atributos que 'realmente' possui sejam descobertos, realçando sua 'identidade social real'.

Nogueira utiliza o termo 'passar' ao caracterizar o processo de interação do tuberculoso com os 'sãos'. É crível que tenha resgatado tal expressão dos estudos sobre relações raciais, em que o fenômeno do 'passing', ou seja, o negro passar-se por branco, era bastante conhecido. Tanto um quanto outro são expressões da manipulação simbólica (e mesmo física) de características indesejáveis e, muitas vezes, indesejadas pelos próprios portadores. O próprio orientador da dissertação de mestrado de Nogueira, Donald Pierson, em sua obra Brancos e pretos na Bahia: estudo de contato racial, publicada em 1942, utilizou-se de tal expressão para descrever as relações sociais estabelecidas entre brancos e morenos/mulatos e a ansiedade e drama psicológico destes últimos quanto à possibilidade de serem 'descobertos', 'desmascarados'. No caso dos tuberculosos analisados em Vozes, os 'desacreditáveis', sujeitos às mesmas expectativas de comportamento que as demais pessoas com as quais convivem, uma vez desconhecido seu estado de saúde, e impossibilitados de desempenhar muitas atividades por serem incompatíveis com o tratamento, entram em um estado de inquietação quase constante. O retraimento leva, no extremo, ao ostracismo social.

No 'ambiente tuberculoso' forma-se um 'espírito de grupo', expresso na tendência de dividir a humanidade entre 'tuberculosos' e 'não tuberculosos' e na tendência à superavaliação da experiência dos 'doentes' em contraste com os 'sãos', bem como, internamente ao grupo dos tuberculosos, entre 'veteranos' e 'novatos'. Surge um acervo de modos de sentir, pensar e agir, percebido em conjunto por doentes e médicos. À medida que se acomoda ao novo meio, substituindo o antigo sistema de hábitos e atitudes pelo novo, que as novas circunstâncias lhe impõem, e à medida que vai reformulando sua filosofia e seus planos de vida, o doente se vê cada vez mais distanciado de seu antigo círculo de relações primárias, pela divergência de experiências e de perspectivas de vida e, consequentemente, de atitudes e valores.

A linguagem, por intermédio de expressões e gírias, passa a representar o mundo e a distância social entre o 'nós' (tuberculosos) e o 'eles' (médicos, enfermeiros, não tuberculosos em geral), incorporando experiências e interesses em comum em oposição aos que estão além dos muros dessa 'comunidade' formada em tão pouco tempo. Termos como 'colega' 
e 'irmão', que significam 'tuberculoso', e 'irmandade', para abranger todo o grupo, sugerem sentimentos de simpatia e solidariedade, o tal espírito de grupo. Estes termos indicam uma tendência de evitar palavras que se refiram diretamente ao estereótipo do qual se quer fugir, incorporado pelo próprio doente durante sua vida de 'são' através da tradição e da leitura.

A tuberculose é vista como doença incurável, e o tuberculoso um indivíduo excessivamente magro "a tossir e escarrar incessantemente, sempre febril e com frequentes hemoptises" (p.91), ainda que à época estudos já mostrassem que pessoas portadoras da doença que não apresentavam quaisquer dessas características, muito pelo contrário, chegavam às estações de cura "gordas, coradas e bem dispostas e ... tipos atléticos" (p.94). Um ex-estudante de curso secundário afirma a Nogueira, por exemplo (p.101): "Pensava que os doentes fossem impressionantes pela magreza, tosse e outros sintomas que sempre pensei existir nesta doença. ... Só pude ter boa impressão depois de estar aqui, pois que o ambiente em que me acho mais parece um colégio de pequenas robustas, que um sanatório."

A pesquisa de Nogueira é uma contribuição fundamental para o estudo do comportamento desviante em sociedades complexas e as relações entre indivíduo e sociedade, tema fundamental da antropologia urbana. A divisão da sociedade entre 'sãos' e 'doentes', quando da análise da tuberculose pulmonar, coloca o problema dos desviantes numa perspectiva patológica, sendo o indivíduo desviante encarado a partir de um ponto de vista médico, opondo comportamento 'normal' e 'anormal'. Ao privilegiar as dimensões social e subjetiva da doença, Nogueira vai além de tal reducionismo.

A perspectiva por ele adotada segue a linha dos chamados estudos interacionistas, uma das mais importantes vertentes da Escola de Chicago, inspirada nas ideias de Georg Simmel a respeito do indivíduo e a caracterização da vida social não como uma união de indivíduos soltos, mônadas, mas como a relação entre eles, sua interação. Para os interacionistas, a noção básica é a de que não existem desviantes em si mesmos, mas uma relação entre indivíduos e grupos que se investem da prerrogativa de definir que tipo de comportamento é legítimo em determinada situação socialmente construída. Os interacionistas repelem homogeneizações culturais sem levar em consideração a forma como os atores sociais envolvidos na interação definem, circunstancialmente, o certo e o errado.

Conforme um dos maiores expoentes interacionistas, Howard Becker, o desvio não é uma qualidade do ato que a pessoa faz, mas sim consequência da aplicação por outrem de regras e sanções ao 'transgressor'. O comportamento desviante, no nosso caso a tuberculose, é o comportamento definido por pessoas concretas, produto do referencial simbólico aplicado pelos atores em interação.

Um dos muitos méritos de Vozes de Campos do Jordão: experiências sociais e psíquicas do tuberculoso pulmonar no estado de São Paulo é revelar que o desvio ou o comportamento desviante é uma criação da sociedade, função das regras sociais que definem situações sociais e os tipos de comportamento apropriados a elas. Sendo o desvio consequência das respostas dos outros ao ato de uma pessoa, os interessados em compreender o comportamento desviante não podem supor que estejam lidando com uma categoria homogênea que dê conta de toda e qualquer situação. O desvio é, portanto, produto de um processo que envolve respostas de outras pessoas a um tipo de comportamento. 


\section{REFERÊNCIAS}

BECKER, Howard.

Uma teoria da ação coletiva. Rio de Janeiro: Zahar. 1976.

DOUGLAS, Mary.

Pureza e perigo. São Paulo: Perspectiva. 1976.

GOFFMAN, Erving.

Estigma: notas sobre a manipulação da identidade deteriorada. Rio de Janeiro: Guanabara. 1988.
PIERSON, Donald.

Brancos e pretos na Bahia: estudo de contato racial. São Paulo: Companhia Editora Nacional. 1.ed., 1942. 1971.

STONEQUIST, Everett.

$O$ homem marginal: estudo de personalidade e conflito cultural. São Paulo: Martins Fontes. 1948.

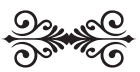

